J. Lake Sci.(湖泊科学), 2021, 33(2): 571-580

DOI 10. 18307/2021. 0222

(c) 2021 by Journal of Lake Sciences

\title{
考虑河道整治工程影响的一维水沙数学模型及其应用
}

\author{
周美蓉, 夏军强**, 邓珊珊, 李志威 \\ (武汉大学水资源与水电工程科学国家重点实验室,武汉 430072)
}

\begin{abstract}
摘 要: 在冲积河流上, 各类河道整治工程的实施一定程度上会影响河床的演变过程. 本文通过改进现有的一维水沙数 学模型, 重点研究护岸及护滩 (底) 这类限制河床进一步冲刷的整治工程对水沙输移及河床冲淤变形的影响. 首先对固定 断面的各节点采用特定的代码进行标记, 以此区分河漫滩、有或无整治工程的主槽区域. 然后对悬沙输移及河床冲淤变 形模块进行改进: 当断面发生淤积时, 其形态调整不受整治工程的影响,淤积量将在整个断面上进行分配; 当发生冲刷 时, 断面形态调整仅发生在未实施工程的位置或者受工程限制但形成了一定厚度淤积层的区域; 在实施了整治工程且无 法提供沙源的区域, 河床冲刷则不会发生. 最后长江中游荆江段 2016 年的模拟结果表明: 考虑整治工程情况时, 改进模型 计算的河道冲刷量偏小且与实测值更为接近;河槽断面形态与实测结果也更为吻合.
\end{abstract}

关键词: 河道整治工程;一维水沙数学模型;悬沙输移;河床冲淤;长江中游;荆江河段

\section{One-dimensional morphodynamic model of channel deformation with the consideration of river regulation works and its application*}

Zhou Meirong, Xia Junqiang ***, Deng Shanshan \& Li Zhiwei

( State Key Laboratory of Water Resources and Hydropower Engineering Science, Wuhan University, Wuhan 430072, P.R.China)

Abstract: A one-dimensional morphodynamic model has been improved to simulate the fluvial processes influenced by large-scale river regulation works, and the focus is paid to investigate the effect of a bank-, shoal- and bed- protection works. In the refined model, different zones of a cross-section are first demarcated by different point codes, including the zones of floodplain and mainchannel with or without engineering. Then the modules of sediment transport and bed deformation are modified. When channel deposition occurs, it is not influenced by regulation engineering and the deposition volume will be allocated at a whole cross-section. However, channel scour will only occur at the unprotected bed or the protected bed with a deposition layer newly formed over the previous simulation period; at the protected bed without sediment to be scoured, erosion is not allowed. Then the Jingiiang Reach of the middle Yangtze River was selected as the study reach. Simulated results for the year 2016 show that the channel scours volume calculated using the improved model was smaller and in closer agreement with the measurements that without the consideration of river regulation works. Besides, the variation in channel geometry calculated by the improved model was more consistent with the measured result.

Keywords: River regulation works; one-dimensional morphodynamic model; sediment transport; bed deformation; middle Yangtze River; Jingjiang Reach

在冲积河流上, 因防洪安全及航槽稳定的需要, 沿程修建了大量河道整治工程, 这些工程对水沙输移及 河床冲淤变形产生了显著影响 ${ }^{[1-5]}$. 因此,在实施了大规模河道整治工程的河段,有必要研究工程对水沙输 移及河床调整的整体影响.

目前考虑河道整治工程影响的数学模型较少, 且已有数学模型多是研究某一特定整治工程引起的局部

* 2020-04-29 收稿; 2020-06-22 收修改稿.

国家重点研发计划 (2016YFC0402303/05) 和国家自然科学基金项目 (51725902,U2040215) 联合资助.

** 通信作者;E-mail:xiajq@whu.edu.cn. 
影响,主要包括水流结构变化、泥沙输移及河床形态的调整 ${ }^{[6-10]}$. 这类模型基本为二维或三维,一部分仅考虑 了工程对水流结构的影响. 如 Giri 等 ${ }^{[7]}$ 采用二维模型模拟了布设有丁坝的弯道水槽中的水流运动特性; 冯 民权等 ${ }^{[8]}$ 采用平面与立面二维模型,计算了导流板周围的流速场, 比较了导流板不同布置方式和尺寸对流 速的影响. 另一部分则进一步考虑了泥沙运动及河床变形. 如潘军峰等 ${ }^{[9]}$ 计算了单个丁坝与丁坝群产生的 流速场与浴量场, 并比较了不同布置方式对局部冲刷坑范围的影响; 间军等 ${ }^{[4]}$ 通过二维模型计算了两种护 滩工程作用下江心滩的变形过程, 发现两者均可实现对心滩头部的守护, 但所引起的河床局部冲淤特性上 存在差异; Minor 等 ${ }^{[10]}$ 则采用三维模型, 模拟了弯道丁坝群附近的紊流结构及泥沙运动过程. 但在一些情况 下, 了解大范围整治工程对较长河段河床调整的整体影响是十分必要的, 特别是在实施了大量整治工程的 重点河段. 与工程附近的局部模拟不同,这类模型需考虑工程实施对整个河道的影响.

长江中下游的护岸及护滩 (底)工程修建规模通常较大, 对河床演变的影响尤为显著. 本文将通过数学 模型, 重点研究这类整治工程的具体影响, 主要包括悬沙输移和河床冲淤变形两个方面. 守护型整治工程实 施后, 整治工程区域河床冲刷被限制, 水流无法从这些区域冲走泥沙; 一方面会影响河段整体的悬沙输移过 程; 另一方面可能加剧冲刷该断面其他未防护位置或影响下游河段的河床冲淤强度 ${ }^{[1]}$. 以往河流数学模型 一般简单地通过改变局部河道边界条件或调整糙率系数的方式考虑整治工程的影响. 本研究基于改进现有 的一维水沙动力学模型, 加强对大规模河道整治工程 (护岸及护滩 (底) 工程) 的处理, 可实现定量地比较考 虑和不考虑整治工程影响下的悬沙输移和河床冲淤变形过程.

\section{1 考虑河道整治工程影响的一维水沙数学模型}

\section{1 模型控制方程}

一维水沙数学模型的控制方程, 主要包括水流连续方程、动量方程、非均匀悬沙不平衡输移方程以及河 床冲淤变形方程 ${ }^{[1]}$, 可分别写成如下式 $(1) \sim(4)$ :

$$
\begin{gathered}
\frac{\partial Q}{\partial x}+B \frac{\partial Z}{\partial t}=q_{l} \\
\frac{\partial Q}{\partial t}+\left(g \cdot A-\alpha_{f} \cdot B \frac{Q^{2}}{A^{2}}\right) \frac{\partial Z}{\partial x}+2 \alpha_{f} \frac{Q}{A} \frac{\partial Q}{\partial x}=\left.\frac{Q^{2}}{A^{2}}\left(\frac{\partial A}{\partial x}\right)\right|_{Z}-g \cdot A\left(J_{f}+J_{l}\right)-\frac{\rho_{l} \cdot q_{l} \cdot u_{l}}{\rho_{m}} \\
\frac{\partial}{\partial t}\left(A \cdot S_{k}\right)+\frac{\partial}{\partial x}\left(A \cdot U \cdot S_{k}\right)=B \cdot \omega_{k} \cdot \alpha_{k}\left(S_{* k}-S_{k}\right)+S_{l k} \cdot q_{l} \\
\rho^{\prime} \frac{\partial A_{\mathrm{b}}}{\partial t}=\sum_{k=1}^{N} B \cdot \omega_{k} \cdot \alpha_{k}\left(S_{k}-S_{* k}\right)
\end{gathered}
$$

式中, $Q 、 Z$ 分别为流量 $\left(\mathrm{m}^{3} / \mathrm{s}\right)$ 和水位 $(\mathrm{m}) ; A 、 B$ 分别为过水断面面积 $\left(\mathrm{m}^{2}\right)$ 和水面宽度 $(\mathrm{m}) ; x 、 t$ 分别为沿程 距离及时间 $(\mathrm{m}$ 和 $\mathrm{s}) ; g$ 为重力加速度, 取值 $9.81 \mathrm{~m} / \mathrm{s}^{2} ; \alpha_{f}$ 为动量修正系数; $J_{f}$ 为水力坡度, 可由公式 $J_{f}=$ $(Q / A)^{2} n^{2} / R^{4 / 3}$ 计算, $R$ 为水力半径 $(\mathrm{m})$, 在宽浅河道水力半径可近似由断面平均水深 $h$ 代替 $(\mathrm{m}), n$ 为床面 的曼宁粘率系数; $J_{l}$ 为断面扩张与收缩引起的局部阻力; $q_{l} 、 \rho_{l} 、 u_{l}$ 分别为出人流的单位河长流量 $\left(\mathrm{m}^{2} / \mathrm{s}\right)$ 、密 度 $\left(\mathrm{kg} / \mathrm{m}^{3}\right)$ 及流速 $(\mathrm{m} / \mathrm{s})$ 在主流方向的分量; $\rho_{\mathrm{m}}$ 为干流浑水密度 $\left(\mathrm{kg} / \mathrm{m}^{3}\right) ; U$ 为断面平均流速 $(\mathrm{m} / \mathrm{s}) ; S_{k}$ 、 $S_{* k} 、 \omega_{k}$ 分别为第 $k$ 粒径组悬沙的分组含沙量 $\left(\mathrm{kg} / \mathrm{m}^{3}\right)$ 、水流挟沙力 $\left(\mathrm{kg} / \mathrm{m}^{3}\right)$ 和浑水沉速 $(\mathrm{m} / \mathrm{s}) ; \alpha_{k}$ 为恢复饱 和系数, 其值多根据实测资料率定; $S_{l k}$ 为出入流的分组含沙量 $\left(\mathrm{kg} / \mathrm{m}^{3}\right) ; \rho^{\prime}$ 为床沙干密度 $\left(\mathrm{kg} / \mathrm{m}^{3}\right) ; N$ 为悬沙 分组数; $A_{\mathrm{b}}$ 为冲淤可动层面积 $\left(\mathrm{m}^{2}\right)$. 其中, 分组水流挟沙力 $S_{* k}=\Delta P_{* k} \cdot S_{*}, \Delta P_{* k}$ 为挟沙力级配, 其值可由 李义天 ${ }^{[12]}$ 提出的方法确定, $S_{\text {* }}$ 为断面挟沙力 $\left(\mathrm{kg} / \mathrm{m}^{3}\right)$, 本文采用张瑞瑾挟沙力公式计算 ${ }^{[13]}$ :

$$
S_{*}=k\left(\frac{U^{3}}{g \cdot h \cdot \omega_{\mathrm{m}}}\right)^{m}
$$

式中, $k$ 为包含量纲的系数 $\left(\mathrm{kg} / \mathrm{m}^{3}\right) ; m$ 为指数; $\omega_{\mathrm{m}}$ 为非均匀悬沙的平均沉速 $(\mathrm{m} / \mathrm{s})$.

\section{2 一维水沙数学模型的改进}

1.2.1 确定河床边界条件 模型的第一个改进:对河漫滩、滩唇、有或无整治工程的主槽区域进行了划分. 在 以往的一维水沙数学模型中, 通常以实测固定断面地形作为初始河床边界条件, 包括断面各节点距左岸的 
距离及相应的河床高程. 在改进后的模型中, 断面上不同区域还需采用特定的代码 $(P C=0 、 1 、 2 、 3)$ 进行标 记(图 1). 首先, 当洪水漫过滩地时,水力条件发生突变,因此有必要区分滩地与主槽区域; 其次, 整治工程 对河床边界条件的影响较大, 故需对有、无工程的主槽区域进行划分; 最后, 完成上述处理后, 将所有实测固 定断面地形和相应的节点代码将作为改进模型的河床边界条件.

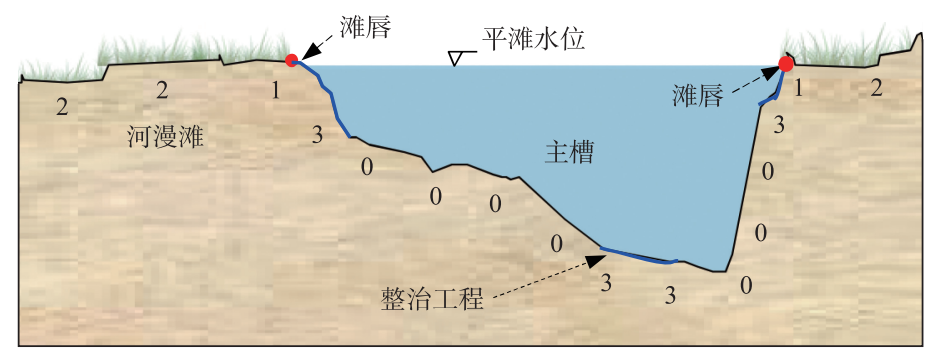

图 1 河漫滩 $(P C=2) 、$ 、滩唇 $(P C=1)$ 及有或无整治工程的主槽区域 $(P C=3$ 或 0$)$ 划分

Fig.1 Determination of the zones of floodplain $(P C=2)$, lips $(P C=1)$, and main-channel zones with and without river regulation works $(P C=3$ or $P C=0$, respectively )

1.2.2 改进输沙及河床变形计算模块 图 2 给出了河道横断面形态示意图. 由图可知,河床在垂向上依次可 分为淤积层、可动层和不可动层; 其中, 淤积层定义为模拟时段内由于泥沙落淤形成的高于初始河床的沙 层, $Z_{i, j}^{\mathrm{b}}$ 代表节点河床高程, $Z_{i, j}^{0}$ 为节点初始河床高程 (设定初始时刻实施工程的区域均无泥沙淤积). 下面 将详细阐述考虑河道整治工程影响时一维模型中输沙及河床变形计算模块的改进方法.

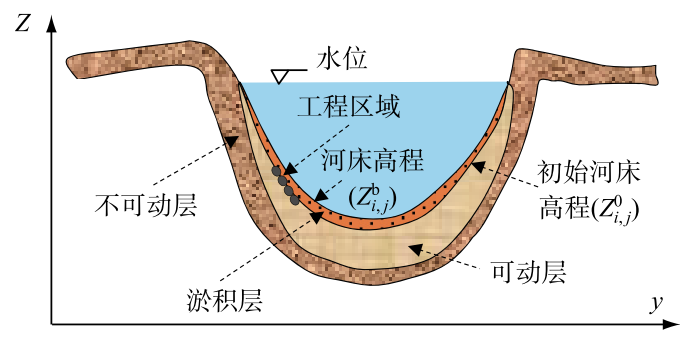

图 2 河道横断面形态示意

Fig. 2 Sketch of a river cross-section

(1) 输沙模块的改进.

首先, 根据公式 (5) 计算得到各固定断面的水流挟沙力 $\left(S_{*_{i}}\right)$. 但河道整治工程限制了河床的冲刷下切, 对悬沙输移产生影响. 故本文通过修正断面水流挟沙力来考虑所产生的影响. 具体修正方法如下:

(i) 当通过比较计算的含沙量与水流挟沙力的相对大小, 判断出固定断面发生淤积时, 其淤积过程不受 整治工程的影响,故断面有效的水流挟沙力 $\left(S_{* i}^{\prime}\right)$ 仍等于原始计算值 $\left(S_{* i}\right)$.

(ii) 当该断面发生冲刷时, 需通过公式 $S^{\prime}{ }_{* i}=S_{i}+\left(S_{* i}-S_{i}\right) \cdot r_{i} \cdot k_{2}$ 修正原始计算的挟沙力数值, 从而计 算得到有效的断面水流挟沙力 $\left(S_{* i}^{\prime}\right) . r_{i}$ 为可冲刷河床宽度 $L_{i}$ 占整个断面湿周 $\left(\chi_{i}\right)$ 的比例. $k_{2}$ 为修正系数, 其值设为 $k_{2}=2-r_{i} \geqslant 1$. 虽然整治工程限制了防护区域的河床冲刷, 但水流可能转而冲刷该断面其他未受防 护的节点, 使得这些节点的冲刷强度有所增加, 系数 $k_{2}$ 一定程度上考虑了此影响. 故 $k_{2}$ 的值需大于 1 , 且 $k_{2}$ 还需与允许冲刷河床比例 $r_{i}$ 相关. 当 $r_{i}=1$ 时, 整个断面均会发生冲刷, 不受工程限制, 故 $k_{2}$ 应等于 1 ; 当 $0<r_{i}<1$ 时, 随着实施工程的宽度比例增加, 水流对该断面上其他未防护节点的冲刷强度愈强, 故 $k_{2}$ 的值 需与可冲刷河床比例 $r_{i}$ 呈反比关系. 为了满足这些要求, $k_{2}$ 最终设定为 $2-r_{\mathrm{i}}$. 当 $r_{i}=0$ 时, $k_{2}=2$. 该参数虽无 法精确地考虑水流转移冲刷的影响,但模拟得到的结果将比不考虑这方面影响的结果更接近实际.

此外, $r_{i}$ 的取值在 $0 \sim 1$ 之间. 当 $r_{i}=0$ 时, 意味着整个断面均受到工程防护, 水流无法从河床上携带起 
泥沙, 故修正断面水流挟沙力 $\left(S_{* i}\right)$ 等于断面含沙量 $\left(S_{i}\right)$, 确保整个大断面不发生冲淤变化; 当 $r_{i}=1$ 时,表 示该断面未实施任何整治工程, 故河床可进行自由冲刷, 无需修改该断面水流挟沙力; 而大多数情况下, 各 固定断面只有部分河床受到工程防护 $\left(0<r_{i}<1\right)$, 此时的首要任务为确定 $r_{i}$ 的值, 之后通过公式 $S_{{ }_{*}}^{\prime}=$ $S_{i}+\left(S_{* i}-S_{i}\right) \cdot r_{i} \cdot k_{2}$ 进行水流挟沙力的修正.

(2) 河床变形模块的改进.

基于修正的断面挟沙力 $\left(S^{\prime}{ }_{* i}\right)$, 通过离散并求解河床冲淤变形方程公式 (4), 得到河床冲淤面积 ( $\Delta A_{\mathrm{b}, i}$ ). 以往一维水沙数学模型未考虑整治工程对河床变形的影响, $\Delta A_{\mathrm{b}, i}$ 通常是平均分配或根据流量加 权分配到固定断面的各个节点上. 而改进的模型充分考虑了整治工程的影响, 对河床冲淤面积的分配模式 进行了修改. 具体如下:

(i) 当固定断面发生淤积时, $\Delta A_{\mathrm{b}, i}$ 依据流量分配到每个节点上, 从而计算得到各节点的河床冲淤厚度 $\left(\Delta Z_{i, j}^{\mathrm{b}}=\frac{\Delta A_{\mathrm{b}, i}}{\sum 0.5\left(q_{i, j}+q_{i, j+1}\right) \Delta B_{i, j}} q_{i, j}, j\right.$ 为断面上所有节点), 其中 $q_{i, j}$ 为节点的单宽流量.

(ii) 当该断面发生冲刷时, 河床形态调整只发生在无整治工程 $(P C=0 、 1 、 2)$ 或有工程但已形成可供冲 刷淤积层的节点上 $\left(P C=3\right.$ 且 $\left.Z_{i, j}^{\mathrm{b}}>Z_{i, j}^{0}\right)$, 故 $\Delta A_{\mathrm{b}, i}$ 只在这些节点上根据流量进行分配 $\left(\Delta Z_{i, j}^{\mathrm{b}}=\right.$ $\frac{\Delta A_{\mathrm{b}, i}}{\sum 0.5\left(q_{i, j}+q_{i, j+1}\right) \Delta B_{i, j}} q_{i, j}, j$ 为允许冲刷的断面节点). 需注意的是, 在实施工程的节点上 $(P C=3$ 且 $Z_{i, j}^{\mathrm{b}}>Z_{i, j}^{0}$ ), 计算得到的河床冲淤厚度 $\left|\Delta Z_{i, j}^{\mathrm{b}}\right|$ 应小于该时刻河床高程与初始河床高程的差值 $\left(Z_{i, j}^{\mathrm{b}}-Z_{i, j}^{0}\right)$; 若大于该值, 则应修改为 $\Delta Z_{i, j}^{\mathrm{b}}=Z_{i, j}^{\mathrm{b}}-Z_{i, j}^{0}$, 由此考虑整治工程对河床下切的限制作用. 此外, 在受工程防护 且无淤积层提供沙源的节点上 $\left(P C=3\right.$ 且 $\left.Z_{i, j}^{\mathrm{b}}=Z_{i, j}^{0}\right)$, 河床不发生进一步的冲刷, 相应的 $\Delta Z_{i, j}^{\mathrm{b}}$ 为 0 .

(iii) 计算得到各节点的冲淤厚度后, 修改各节点高程 $\left(Z_{i, j}^{\mathrm{b}}=Z_{i, j}^{\mathrm{b}}+\Delta Z_{i, j}^{\mathrm{b}}\right)$.

\section{2 模型率定与验证}

本文选取长江中游荆江段作为研究对象, 利用该河段 2015 年的实测数据, 对改进的模型进行率定, 并 用 2016 年的实测资料进行验证. 总体而言, 模拟得到的结果与实测过程符合较好. 但需要指出的是, 由于三 峡工程的运用及荆江段二元结构河岸的土体特性,该河段近年来崩岸频发,故河岸崩退对该河段的泥沙输 移及河床形态调整亦有显著影响. 已有研究将崩岸力学模型耦合到一维水沙动力学模型中, 用于计算床面 冲淤与河岸崩退过程 ${ }^{[11]}$. 由于 2015-2016 年荆江段崩岸总体较弱, 故模型中暂不考虑河岸崩退过程计算. 如遇到河岸崩退较为显著的年份, 一维水沙数学模型还需增加崩岸模块, 可使计算与实测的断面形态更为 吻合.

\section{1 研究河段概述}

荆江段全长约 $347 \mathrm{~km}$, 位于枝城和城陵矶之间, 分为上、下荆江. 其干流水沙通过松滋口、藕池口、太平 口分流人洞庭湖 (图 3), 洞庭湖再汇集湖南 “四水” 后又于城陵矶处重新汇人干流. 该河段为典型的弯曲分 汉河道, 由 16 个河弯组成, 河弯处分布着大量洲滩. 进口枝城断面位于三峡大坝下游 $102 \mathrm{~km}$, 三峡及其上游 水库群的运用使得该河段冲刷显著, 2002-2017 年累计冲刷量达 $10.5 \times 10^{8} \mathrm{~m}^{3}$ (平滩河槽). 此外, 为维护防 洪及航运安全, 该河段修建了大规模的整治工程. 截至 2016 年,已完成的护滩 (底) 工程主要包括: 枝江一江 口河段航道整治一期工程、长江中游荆江河段航道整治工程 (昌门溪至熊家洲段工程)、腊林洲守护工程、三 八滩应急守护一、二期工程及沙市河段航道整治一期工程、瓦口子一马家咀航道整治工程等, 主要工程的分 布见图 3. 在护岸工程方面, 近 60 年来荆江干流完成护岸长度约 $252 \mathrm{~km}$, 上荆江实施了长达 $123 \mathrm{~km}$ 的护岸 工程,在下荆江守护岸线长度为 $129 \mathrm{~km}$.

\section{2 计算条件}

在模型的率定和验证过程中, 以枝城站日均的流量、含沙量和悬沙级配资料作为进口边界条件; 同时采 用螺山站的日均水位过程作为出口边界条件. 需指出的是, 莲花塘站是荆江段的出口水位站, 但该站无流量 及含沙量资料. 为方便模型率定, 将研究范围扩展到了莲花塘下游 $35 \mathrm{~km}$ 的螺山水文站. 图 4 给出了 2015 年和 2016 年研究河段进、出口断面的水沙边界条件. 此外, 还将“三口” 分流的日均流量、含沙量和悬沙级配 


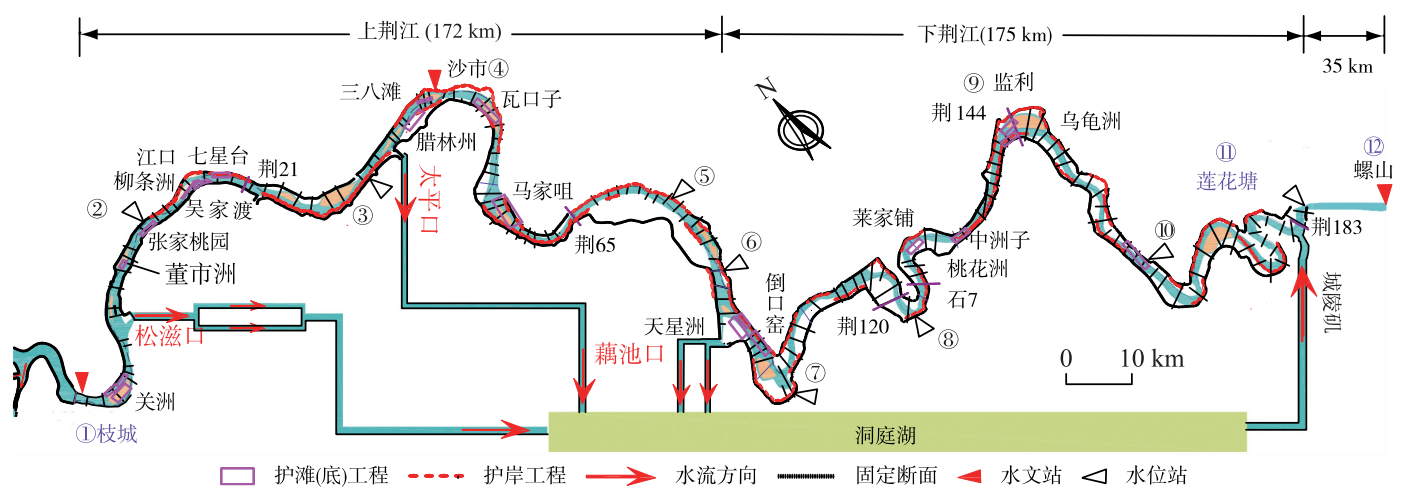

图 3 研究河段示意图(沿程共设有 12 个水文或水位站,(1)枝城、(2)家店、(3)陈家湾、(4)沙市、(5)郝穴、

(6)新厂、(7)石首、(8)调弦口、(9)监利、(10广兴洲、(11莲花塘、(12)螺山)

Fig.3 Sketch of the study reach, covering the locations of 12 hydrometric and level gauge stations

作为侧向边界条件; 荆江段汗后实测的 185 个固定断面地形、各节点代码作为初始河床边界条件 (实测时间 分别为 2014 年 11 月和 2015 年 10 月); 72 个固定断面的实测床沙级配作为初始床沙资料(实测时间分别为 2014 年 11 月和 2015 年 10 月), 其余断面的初始级配由这些实测值插值求得. 为研究整治工程对河床演变 的影响,还需收集荆江段护岸、护滩(底)工程的分布及规模资料. 首先, 根据工程布置图, 可大致确定护岸工 程的所在位置及其沿河长方向的防护范围, 以及护滩 (底) 工程的规模. 荆江段各固定断面的间距在 $0.48 \sim$ $6.72 \mathrm{~km}$ 之间, 平均值约为 $2.0 \mathrm{~km}$, 而护岸工程覆盖长度较大(图 3). 根据护岸工程布置图, 将工程经过的固 定断面的防护区域进行标记, 并认为断面间标记位置之间的区域均为工程守护区域. 然而护岸工程沿河中 心方向的施工宽度无法从工程布置图获取, 故采取以下方法综合确定: (1)采用地形套汇的方法进行估计, 若 河床连续 3 年未发生冲刷则认为这部分河床受工程防护; (2)主流的贴岸冲刷和迎流顶冲是造成河岸崩退的 重要原因,根据护岸工程的实施原则,一般需将抛石范围延伸至深泓处, 以免主流对河床的剧烈冲刷会破坏 护岸结构,故可认为从岸顶到深泓范围内均受工程守护, 不发生冲刷. 此外, 模型中水流与泥沙的计算为非 耦合计算,计算时间步长为 $30 \mathrm{~s}$.
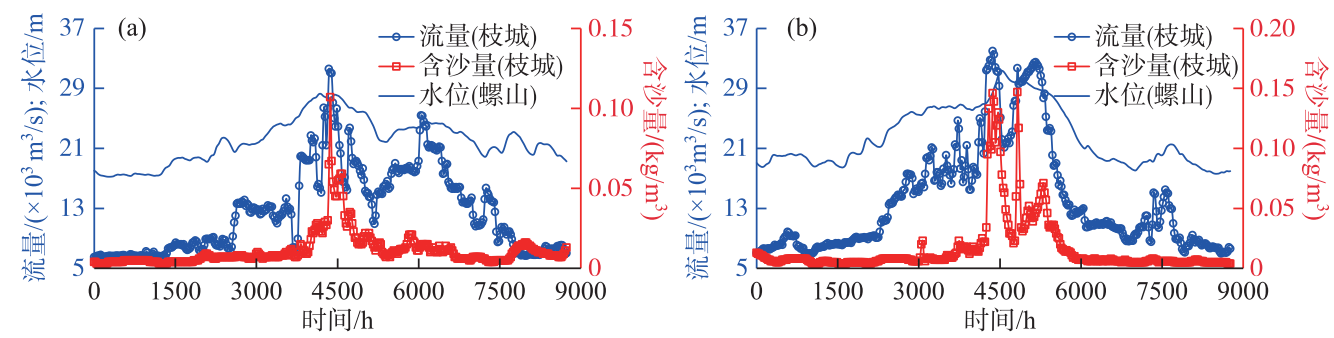

图 4 模型率定和验证的进、出口边界条件:（a）2015 年; (b) 2016 年

Fig.4 Boundary conditions for model calibration and verification: (a) 2015; (b) 2016

\section{3 计算步骤}

(1) 模型的初始及边界条件给定; (2) 水流模块计算:采用 “Preissmann”隐格式离散一维水流控制方程 式(1) (2), 并用追赶法求解,计算河道内各断面的水流条件; (3) 泥沙输移模块计算:基于 $t-1$ 时刻修正得 到的断面有效水流挟沙力,采用迎风格式离散并求解式 (3), 进而计算新水流条件下 ( $t$ 时刻) 各固定断面的 悬移质含沙量 $\left(S_{i}\right)$; (4) 水流挟沙力计算: 根据式 $(5)$ 计算新水流条件下各断面的水流挟沙力 $\left(S_{* i}\right)$, 并对 其进行修正, 得到 $t$ 时刻有效的断面水流挟沙力 $\left(S^{\prime}{ }_{* i}\right)$; (5) 河床变形模块计算:在修正的水流挟沙力条件 下, 采用显格式离散并求解式 (4), 计算河床冲淤面积 $\left(\Delta A_{\mathrm{b}, i}\right)$ 并修改河床地形, 其冲淤面积分配模式在有、 
无整治工程的区域有所不同; (6) 在新河床地形条件下,重新计算水流、泥沙条件,用于下一时刻的计算.

\section{4 模型率定结果及分析}

本研究选取了荆江段 2015 年 1 月 1 日至 12 月 31 日的水沙系列,对改进的模型进行率定, 模拟了该时 段的水沙输移过程, 从而确定模型的最优参数.

2.4.1 流量和水位变化 在改进的模型中, 河漫滩和主槽的䊁率将分别确定. 河漫滩的曼宁䊁率系数通常设 为常数, 在荆江段低滩及高滩粘率分别取为 $0.025 、 0.04$. 而主槽的粮率则通过率定得到, 先假定研究河段内 各水文或水位站所在断面 (控制断面) 的流量一䊁率关系, 并认为河段内其他断面某一流量下的粘率系数可 由相邻两个控制断面同流量下的糙率值通过线性插值得到; 然后通过调试这些控制断面的流量一精率关系, 使得研究河段内各水文站或水位站计算的水位、流量过程与实测情况能较好地符合. 计算结果表明: 在沙 市、监利及螺山站, 计算与实测的流量过程一致, 平均流量的相对误差均为 3\%左右 (图 5a c ) ; 在枝城、沙市 及监利站,平均水位的绝对误差则均小于 $0.3 \mathrm{~m}$ (图 $5 \mathrm{~d} \sim \mathrm{f}$ ). 故该模型可很好地模拟典型断面流量及水位随 时间的变化过程.
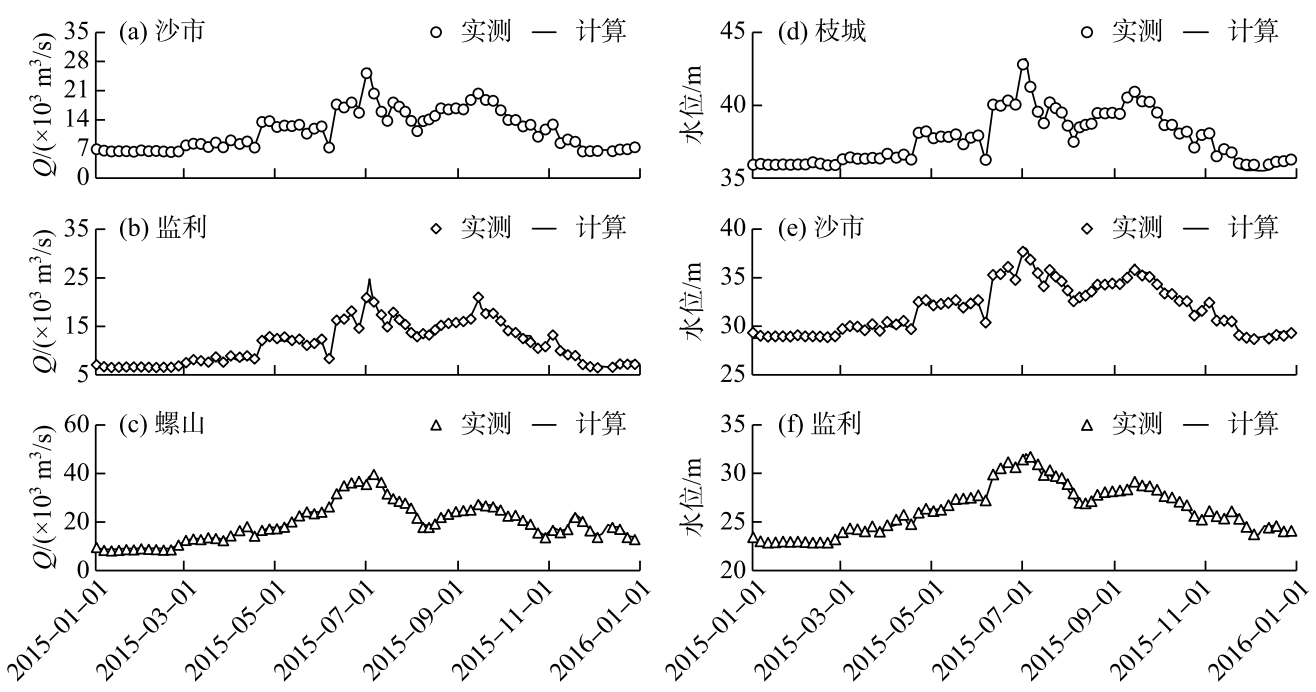

图 52015 年各水文站计算与实测的流量及水位过程比较: ( a c ) 流量; $(\mathrm{d} \sim \mathrm{f})$ 水位

Fig.5 Comparisons between the calculated and measured discharge and water level of each hydrological station in 2015: (a-c) discharge; $(d-f)$ water level

2.4.2 含沙量变化 图 6 给出了 2015 年沙市、监利及螺山站计算和实测含沙量的变化过程. 由图可知,三站 计算与实测的平均含沙量相对误差分别为 33\%、30\%和 $13 \%$. 总体而言, 改进的模型可较好地模拟含沙量过 程,但其误差高于流量和水位误差. 此外, 模型计算中张瑞瑾挟沙力公式系数 $k$ 取为 $0.05 \mathrm{~kg} / \mathrm{m}^{3}$, 而指数 $m$ 在各断面也均为常数 1.55. 分组泥沙恢复饱和系数 $\alpha_{k}$ 根据实测资料率定得到: 在本次计算中, 当发生淤积 时, $\alpha_{k}$ 取值为 0.15 ; 而发生冲刷时, $\alpha_{k}$ 设为 0.20 .

\section{5 模型验证结果}

本研究验证过程选取了荆江段 2016 年 1 月 1 日至 12 月 31 日的水沙系列, 在率定得到的最优参数条件 下 (如曼宁糙率系数、挟沙力公式参数、恢复饱和系数等), 验证改进模型的模拟精度. 结果表明: 沙市、监利 和螺山站计算和实测流量的平均相对误差为 3\% 5\% (图 7a c), 而枝城、沙市、监利站水位的平均绝对误差 均在 0.1 0.3 m 之间. 此外, 沙市、监利和螺山站计算与实测悬移质含沙量的平均相对误差分别为 $49 \%$ 、39\% 和 $20 \%$; 最大计算含沙量分别为 $0.198 、 0.204$ 和 $0.296 \mathrm{~kg} / \mathrm{m}^{3}$, 与实测值 $\left(0.328 、 0.210\right.$ 和 $\left.0.329 \mathrm{~kg} / \mathrm{m}^{3}\right)$ 相比, 除沙市站外差别均较小 (图 7d f).

图 8 给出了 2016 年荆江段沿程最高、最低水位 $\left(Z_{\text {max }}\right.$ 和 $\left.Z_{\text {min }}\right)$ 计算与实测值的比较结果. 由图可知, 模型 

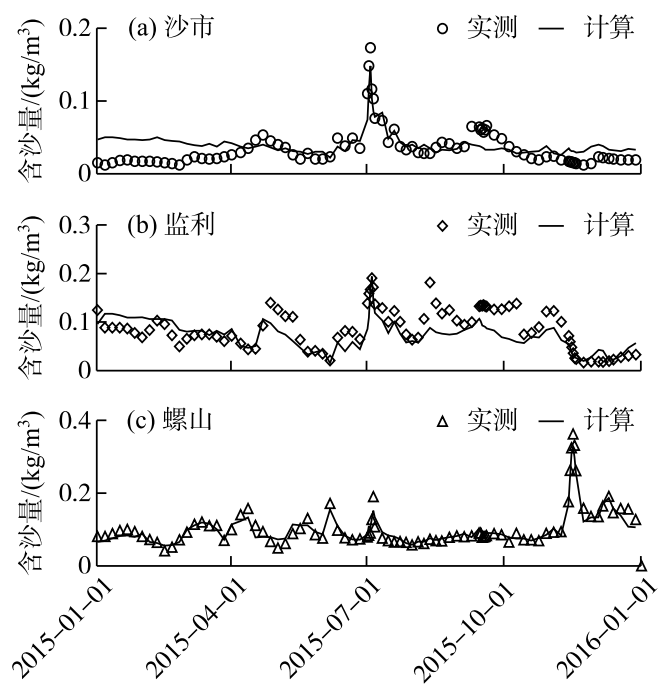

图 62015 年各水文站计算与实测含沙量过程比较

Fig. 6 Comparisons between the measured and calculated sediment concentrations of each hydrological station in 2015
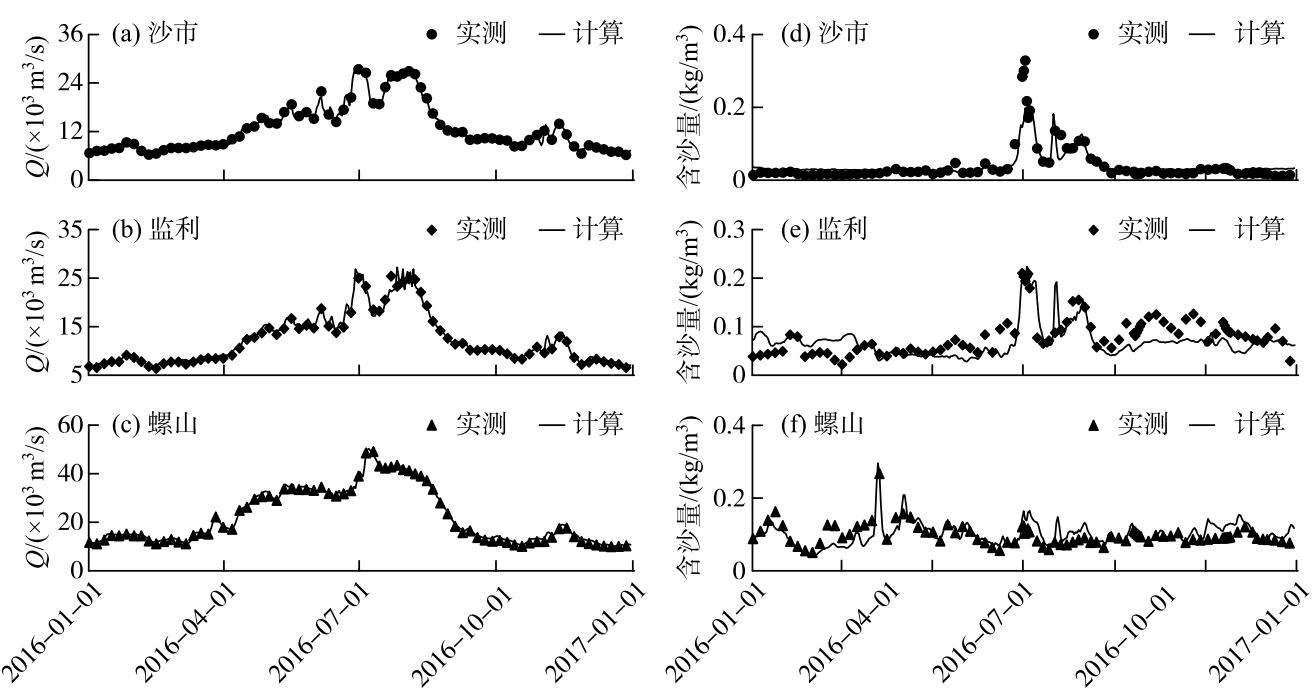

图 72016 年各水文站计算与实测的流量及含沙量过程比较: ( a c) 流量; (d f ) 含沙量

Fig.7 Comparisons between the calculated and measured discharge and sediment concentrations of each hydrological station in 2016: $(a-c)$ discharge; $(d-f)$ sediment concentrations

的计算结果与实际符合较好. 例如, 螺山站上游 3 个水文站 (枝城、沙市、监利) 的实测最高水位分别为 $43.48 、 39.06$ 和 $34.13 \mathrm{~m}$, 与计算值 43.50、38.29、34.09 m 十分接近. 而最低水位计算值与实测值绝对误差均 在 $0.2 \sim 0.7 \mathrm{~m}$ 之间, 误差亦很小. 从总体上看,改进模型的计算精度较高.

\section{3 讨论}

众所周知,河道整治工程会对悬沙输移及河床冲淤变形过程产生较大的影响. 故本研究基于 2016 年荆 

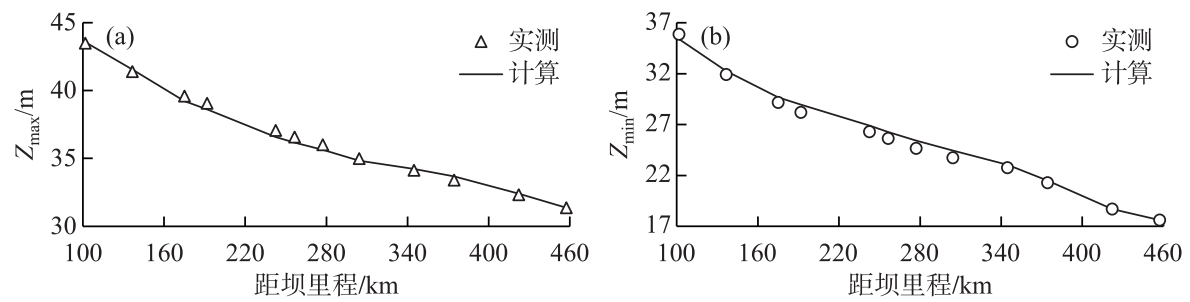

图 82016 年计算与实测的沿程最高和最低水位比较: ( a ) 最高水位; (b) 最低水位

Fig. 8 Comparisons between the measured and calculated water levels in 2016 along the study reach:

(a) maximum water level; (b) minimum water level

江段的实测资料, 通过改进的一维水沙数学模型, 进一步对比计算了该河段在有无考虑工程影响下的悬沙 输移及河床变形过程.

\section{1 河道整治工程对悬沙输移的影响}

整治工程对整个河段悬沙输移的影响主要体现在两个方面. 一方面, 整治工程的实施改变了河段输沙 量,其限制河床冲刷的作用使得整个河段的输沙量有一定程度的减小. 采用输沙率法计算的荆江段 (枝城一 螺山) 2016 年实测冲刷量为 3439 万 $\mathrm{t}$, 而考虑整治工程影响时计算得到的冲刷量为 4021 万 $\mathrm{t}$, 相较于不考虑 工程的模拟结果 (冲刷量 4246 万 $\mathrm{t}$ ) 更接近于实测值. 另一方面, 整治工程的实施影响着含沙量的沿程分布. 计算结果表明, 未考虑工程的模型计算得到的枝城一螺山段 2016 年含沙量总体上大于考虑工程影响的含沙 量. 在计算时段内,两者的绝对差值在 $0 \sim 0.09 \mathrm{~kg} / \mathrm{m}^{3}$ 之间. 图 9 给出了 4 个模拟时刻有、无考虑工程影响的 沿程含沙量对比图. 由图可知,4 个模拟时刻的含沙量平均相对差值分别为 $12.0 \% 、 2.5 \% 、 9.9 \%$ 和 $8.5 \%$.

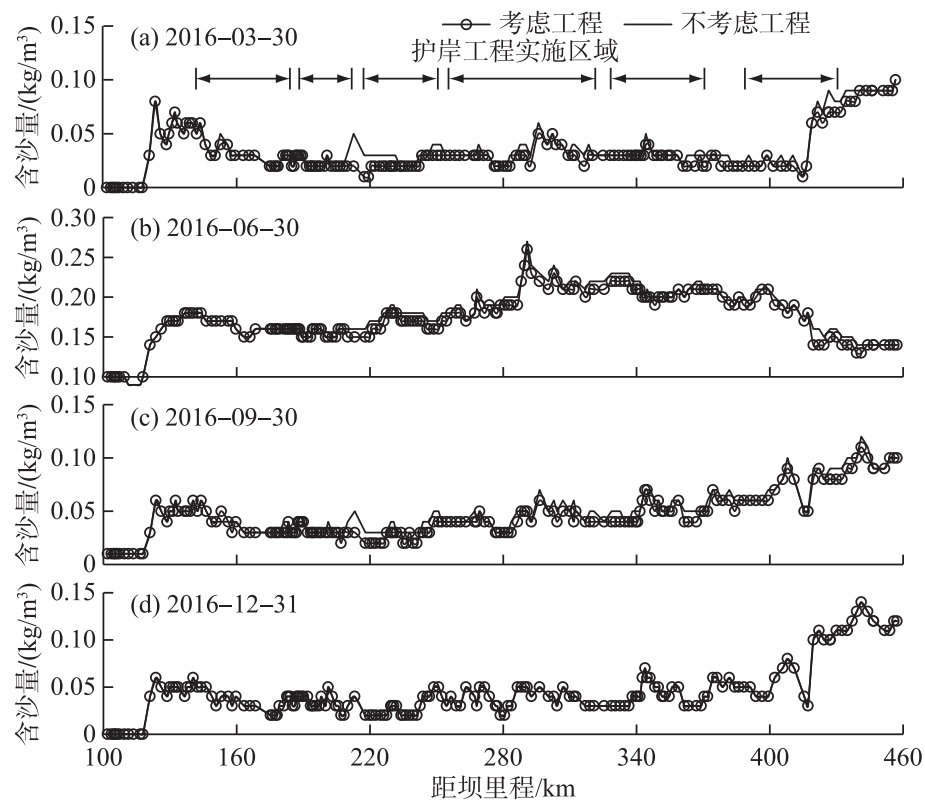

图 92016 年有、无考虑整治工程影响的沿程含沙量对比

Fig.9 Comparisons between the model-calculated suspended sediment concentrations with and without the consideration of regulation works along the study reach in 2016 
理的,但分析考虑工程与否对模拟结果的影响是可行的. 由图 10 可知, 考虑整治工程影响后, 模拟得到的断 面形态更符合实测断面形态. 例如,荆 21 、荆 65 断面主槽的部分区域受工程防护,使河床无法进一步冲刷. 当模型不考虑此影响时, 模拟结果显示该区域 (护底位置) 河床继续下切, 平均下切深度分别达 $0.67 \mathrm{~m}$ 和 $1.14 \mathrm{~m}$, 这显然与实际情况不符 (图 10a b). 如图 10e 所示, 护滩工程的实施亦限制了江心洲的冲刷; 当不 考虑工程影响时, 该江心洲右缘将发生冲刷, 不符合实际. 此外, 整治工程的实施也影响下游河段的河床变 形过程. 如荆 120 断面虽未受到工程守护,但上游河段大规模工程的实施,使得水流无法从河床携带足够的 泥沙, 导致该断面计算的含沙量有所减小, 淤积强度减弱. 当不考虑工程影响时, 计算得到的河床平均淤积 厚度达 $0.35 \mathrm{~m}$; 考虑工程影响后, 该值减小为 $0.08 \mathrm{~m}$ (图 10c), 更符合实际发生冲刷的情况. 而石 7 断面上游 河段受到工程守护, 致使该断面冲刷有所加剧. 在不考虑工程影响时, 计算得到的河床平均下切深度为 0.14 $\mathrm{m}$; 而考虑工程影响时, 该值为 $0.21 \mathrm{~m}$ (图 $10 \mathrm{~d}$ ), 更接近实际下切深度 $0.38 \mathrm{~m}$. 同样在不考虑工程影响下, 模 拟结果表明荆 183 断面能冲刷下切 $0.65 \mathrm{~m}$, 而实际上床面淤高 $0.77 \mathrm{~m}$; 通过考虑工程影响, 该断面则呈淤积 状态,平均淤积厚度为 $0.02 \mathrm{~m}$ (图 10f). 若不在模型中考虑整治工程,上述影响将被忽略.

-- 实测(2015-10) - 实测(2016-11) …… 考虑工程(2016-12-31) - 不考虑工程(2016-12-31)
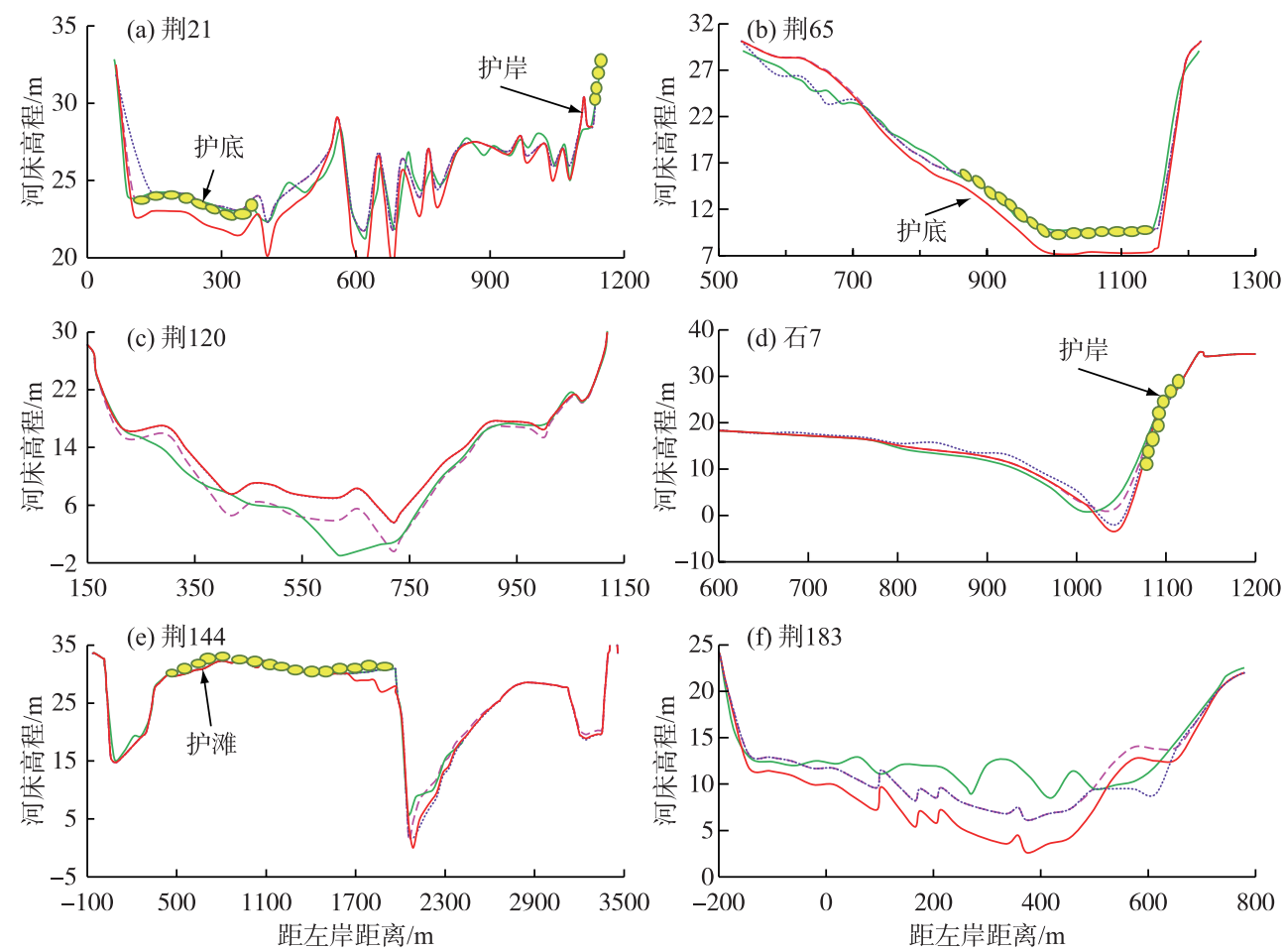

图 10 有、无考虑整治工程影响的典型断面形态对比

Fig.10 Comparisons between the measured and calculated cross-sectional profiles with and without river regulation works being considered at different sections

\section{4 结论}

本文对一维水沙动力学模型进行了改进, 用于模拟河道整治工程影响下的河床调整过程, 并将该模型 应用到长江中游荆江河段. 结论如下:

1) 建立了考虑河道整治工程影响的一维水沙数学模型. 首先在确定河床边界条件时, 在横向上对有无 工程的区域进行划分, 在垂向上将河床分层. 然后在此基础上, 对模型中的输沙及河床冲淤变形模块进行改 
进: 淤积可能发生在河床的任意区域; 但冲刷只会发生在未实施整治工程或前期模拟时段内形成了可供冲 刷淤积层的区域上,在有工程防护且无法为水流冲刷提供沙源的位置,河床下切则不会发生. 最后分别采用 2015 年和 2016 年荆江段的实测资料, 对模型进行率定和验证, 结果表明改进后的模型可较准确地模拟水沙 的输移过程.

2) 定量分析了河道整治工程对悬沙输移和与河床冲淤变形过程的影响. 2016 年荆江段的模拟结果表 明: 采用输沙率法计算的荆江段 (枝城一螺山) 2016 年实测冲刷量为 3439 万 $\mathrm{t}$, 而考虑整治工程影响时计算 得到的冲刷量为 4021 万 $\mathrm{t}$, 相较于不考虑工程的模拟结果 (冲刷量 4246 万 $\mathrm{t}$ ) 更接近于实测值. 此外, 改进模 型计算的河道断面形态与实测数据吻合更好. 这是由于模型考虑了整治工程对河岸崩退、床面下切及洲滩 冲刷的限制作用,以及水流无法从被工程防护区域筫取足够的泥沙而改变其他区域冲淤强度的影响.

\section{5 参考文献}

[ 1 ] Yu WC, Lu JY eds. Bank erosion and protection in the Yangtze River. Beijing: China Water Power Press, 2008. [余文 畴, 卢金友. 长江河道崩岸与护岸. 北京: 中国水利水电出版社, 2008.]

[ 2 ] Zhang HW, Zhang JH, Zhong DY et al. Regulation strategies for wandering reaches of Lower Yellow River. Journal of Hydraulic Engineering, 2011, 42(1) : 8-13. [张红武, 张俊华, 钟德钰等. 黄河下游游荡型河段的治理方略. 水利学 报, 2011, 42(1): 8-13.]

[ 3 ] Nakagawa H, Zhang H, Baba Y et al. Hydraulic characteristics of typical bank-protection works along the Brahmaputra/ Jamuna River, Bangladesh. Journal of Flood Risk Management, 2013 , 6(4) : 345-359. DOI: 10.1111/jfr3.12021.

[ 4 ] Yan J, Liu HH, Yue ZY et al. Numerical simulation of impact of central bar protection engineering on channel scour and deposition characteristics. Chinese Journal of Hydrodynamics, 2012, 27(5) : 589-596. [闻军, 刘怀汉, 岳志远等. 心滩 守护工程对航道冲淤特性影响的数值模拟. 水动力学研究与进展, 2012, 27(5) : 589-596.]

[ 5 ] Liu Y, Wang F, Li YT. Objective river pattern of waterway regulation of goose-head-shaped anabranching channel in the Middle and Lower Yangtze River. Journal of Hydraulic Engineering, 2015, 46(4) : 443-451. [刘亚, 汪飞, 李义天. 长 江中下游鹅头型汉道航道整治目标河型研究. 水利学报, 2015, 46(4): 443-451.]

[6] Asaro G, Paris E. The effects induced by a new embankment at the confluence between two rivers: TELEMAC results compared with a physical model. Hydrological Processes, 2000, 14(13): 2345-2353.

[ 7 ] Giri S, Shimizu Y, Surajate B. Laboratory measurement and numerical simulation of flow and turbulence in a meanderinglike flume with spurs. Flow Measurement and Instrumentation, 2004, 15(5/6) : 301-309. DOI: 10.1016/j.flowmeasinst. 2004.05.002.

[ 8 ] Feng MQ, Fan SF, Zheng BM et al. Research on way to arrange vanes and efficiency of diversion. Engineering Journal of Wuhan University, 2009, 42(1) : 87-91, 95. [冯民权, 范术芳, 郑邦民等. 导流板的布置方式及其导流效果. 武汉 大学学报:工学版, 2009, 42(1): 87-91, 95.]

[ 9 ] Pan JF, Feng MQ, Zheng BM et al. Two-dimensional numerical simulation on spur dike circumfluence and local scour hole. Journal of Sichuan University: Engineering Science Edition, 2005, 37(1) : 15-18. [潘军峰, 冯民权, 郑邦民等. 丁坝绕流及局部冲刷坑二维数值模拟. 四川大学学报:工程科学版, 2005, 37(1) : 15-18.]

[10] Minor B, Rennie CD, Townsend RD. “Barbs” for river bend bank protection: Application of a three-dimensional numerical model. Canadian Journal of Civil Engineering, 2007, 34(9) : 1087-1095. DOI: 10.1139/107-088.

[11] Xia JQ, Deng SS, Zhou MR et al. One-dimensional coupled modeling of bed evolution and bank erosion processes in the Middle Yangtze River. Chinese Science Bulletin, 2019, 64(7): 725-740. [夏军强, 邓珊珊, 周美蓉等. 长江中游河道 床面冲淤及河岸崩退数学模型研究及其应用. 科学通报, 2019, 64(7) : 725-740.]

[12] Li YT. A preliminary study on bed-material gradation composition at a quasi-equilibrium state. Journal of Sediment Research, 1987, (1) : 82-87. [李义天. 冲淤平衡状态下床沙质级配初探. 泥沙研究, 1987, (1) : 82-87.]

[13] Tan GM, Fang HW, Dey S et al. Rui-Jin zhang's research on sediment transport. Journal of Hydraulic Engineering, 2018, 144(6) : 02518002. DOI: 10.1061/( asce) hy.1943-7900.0001464. 